\author{
Marek Pawlik \\ dr inż. \\ Instytut Kolejnictwa \\ mpawlik@ikolej.pl
}

\title{
Rail safety in the context of relationships between directives on safety and interoperability - analysis from the point of view of the essential requirements of the essential 'security'
}

\begin{abstract}
The article presents relationships between railway safety directive and railway interoperability directive. The carried out analysis starts from the definition of the railway interoperability and is based on essential requirement of 'safety'. Ten safety requirements areas were indicated, which are contained in the Technical Specifications for Interoperability TSIs. The article takes into account: degraded situations, construction safety, electrical safety, protection against unauthorised access and fire, influence of forces from rolling stock on track and wheel-rail stability requirements, control command and signalling, influence of traction power supply systems on signalling equipment, operational rules and staff qualifications, panic countervail, as well as informatics support for safety. The article complements analyses, which will be presented in the following issue of the journal.
\end{abstract}

Keywords: Railway transport; Safety; Interoperability; Essential requirements; Technical Specifications for Interoperability TSI

\section{Introduction}

There is no doubt that the safety of rail transport is a necessary condition, but not sufficient, for the economic success of the railway as a mode of transport. Therefore, the safety of rail transport is dedicated to the Directive of the European Parliament and the Council of the European Union on the security of the Community's railways [1]. The better known and widely discussed, however, is the Directive on the interoperability of the Community rail system [2], according to which 'security' is one of the essential requirements that must be met to a railway line or vehicle are considered as interoperable. Linking interoperability with security is not recognized in practice. The most important reason for this is often found very simplistic perception of interoperability. Significant is the fact that rail transport safety is seen in the dimension of technical solutions but not the systemic assessment of risk and the conditions for its acceptance.

The European law as basic documents Safety Directive regards six regulations that define common security methods (Common Safety Methods - CSM) and the decisions that define the values of common safety objectives (Common Safety Targets - CST). At the same time, eleven technical specifications for interoperability (Technical Specifications for Interoperability - TSI) should be regarded in European law as basic documents complemented the directive on interoperability. In Polish law as basic documents Safety Directive should be regarded regulation defining safety indicators (Common Safety Indicators - CSI), the requirements for safety management systems and rules for obtaining formal documents confirming compliance with safety requirements by the railway infrastructure managers, railway carriers and users of railway siding [3-5]. Simultaneously, the Polish law as basic documents complemented the directive on interoperability should be considered a regulation on type certificates and permits for commissioning [6-7] and associated with them regulation 
with independently released list complementing it [8-9] defining the relevant national technical specifications and standardization documents. Their use enables the essential requirements for interoperability of the railway system, including the essential requirement 'safety'.

The aim of this article is to demonstrate a direct relationship between the security approach adopted in the directive on safety [1] and 'security' as a requirement of the Directive on the interoperability [2] and an indication of the consequences of such a link to the functioning of the railway infrastructure managers, railway carriers and users of railway siding.

\section{Interoperability}

Interoperability is often seen as a degree of unification of technologies used in railway transport, which provide the possibility of passing through the borders between different countries (i.e. various infrastructure managers) without changing the traction vehicle (i.e. locomotive) and without changing the driver and, therefore, without stopping the trains at the border. This perception of interoperability is very narrow and consequently actually not true. Although still many trains perceived as an international locomotive are changed at border stations due to technical differences, we also have many examples of trains that are not interoperable, and pass freely across borders. An example can be even trains between Warsaw and Berlin. Neither these trains, nor routes used by them and train stations are not interoperable. We know that not only there are no formal documents that would confirm such conformity, but we also know that the used infrastructure and rolling stock are not fully compatible with the requirements of interoperability. We also know that there are many technical differences between railway infrastructure in Poland and Germany, and noninteroperable trains moving along non-interoperable infrastructure link Warsaw and Berlin easily crossing the boundary between the railway networks. So, what is interoperability?

\section{The definition of interoperability and essential requirements}

Interoperability of the rail system is:

"The ability of a railway system to allow the safe and uninterrupted movement of trains on the characteristics appropriate for the given railway lines, depended on all the technical, legal and operational conditions which ensures fulfilling the essential requirements."

Therefore, the key to understanding the interoperability are essential requirements. For railway transport, six essential requirements were defined. They are: safety, reliability, health, environmental protection, technical compatibility and availability.

The essential requirement 'availability' needs to adapt railway stations (coming to and going out of platforms) and rolling stock (traction units and passenger carriages) to the needs of disabled persons and persons with reduced mobility, by means of the elimination of all kinds of barriers that hinder the use of railway transport by such persons. Among people with reduced mobility are also taken into account the elderly. 
The essential requirement 'technical compatibility' requires such technical solutions that will guarantee the consistency of the technical railway transport. The easiest discernible way is the agreement of rolling stock with infrastructure. Non-compliance, such as between track and loading gauge, or width of the pantographs with zigzags of track network, would create new technical barriers to the movement of vehicles. Intention meanwhile, is quite the opposite, interoperable solutions to ensure technical compatibility on the European scale by eliminating technical barriers still exist. The essential requirement 'technical compatibility' is also the mutual compatibility of different technical solutions used on the line or station, or the mutual compatibility of different technical solutions used in a specific type of rolling stock. In the case of lines and stations, the preservation of 'technical compliance' is necessary to ensure the proper operation of various types of interfaces, for example, a proper cooperation of junction drives with switches or devices controlling the movement of trains built to the neighbouring stations movement. In the example of the rolling stock interfaces can be, for example, couplers.

The essential requirement 'environment' requires the resignation from the use of materials harmful to the environment because of their physical and chemical properties. This applies, for example, to soil contamination or the release of harmful substances into the atmosphere in the exhaust gases. This requirement also includes designing and building power systems in a manner to be electromagnetically compatible with the installations, equipment as well as public and private networks with which they might interfere.

The essential requirement 'health' determines that trains and railway infrastructure must not use materials that may, because of the way they are used, constitute a health hazard to persons having access to them.

With respect to the essential requirement 'reliability' is defined durability of solutions and maintenance of rules for all elements and systems used in infrastructure and rolling stock to ensure uninterrupted movement of trains which was directly invoked in the definition of interoperability.

The fulfilment of these five requirements would not allow the proper operation of railway transport, if not the essential requirement 'safety'. It is very widely understood. It clearly reflects the resulting directly from the law statement that the design, construction and installation, maintenance and monitoring of safety-critical components, and particularly of the components involved in train movements must guarantee safety at the level corresponding to the aims laid down for the network, including in particularly difficult conditions.

The essential requirements are defined at the level of Directive [2]. Descriptions of all six requirements for the railway system as the whole and for individual subsystems are included in the four-page Annex III. These descriptions are very long. The confirmation that a particular installation or a specific type of rolling stock meets the essential requirements based on the same general definition of the essential requirements is not possible. To confirm that a particular system or a specific type of rolling stock meets the essential requirements was possible in specific documents identified as Technical Specifications for Interoperability (TSI specifications) the technical, legal and operational conditions should be precise. Their observance allows for fulfilling the essential requirements. Compliance with these requirements is a prerequisite for recognition of specific solutions for interoperability, thus meeting the essential requirements, and so among other 'safe'. 


\section{The essential requirement 'safety'}

This essential requirement "safe" was defined in many areas. Based on the law regulations, ten areas can be separated: safety failures, security, construction, electrical safety, protection against access and against fire, impact of forces from the rolling stock on the track and cooperation wheel-rail, control of rail traffic, the impact of power system controls, movement regulations and qualifications of personnel, prevention against panic and IT support of railway safety.

\section{Security failure}

The mentioned-above statement is that: design, construction and installation, maintenance and monitoring of critical components for safety, and particularly the components involved in train movements must guarantee safety at the level corresponding to the aims laid down for the network, including particularly difficult conditions. This statement applies to both elements of the track, as well as to equipment of areas accessible to passengers (platforms, passages, railway stations,...), systems and railway traffic control devices and power traction, as well as parts and accessories of vehicles. For example, a damage in the switch machine should not cause risk in crossover switch for a moving train as it leads to derail of the train. Thus axles and wheels must be designed, installed, monitored and maintained in such way to safety be guaranteed at the appropriate level. The required level of security depends on the component and the objectives of security related to the nature of the network and rolling stock. Moreover, it is necessary to take into account the different operating conditions that may occur during the life of the individual components, for example, winter conditions.

\section{Construction safety}

It is necessary to ensure the safety of all persons using the railway, in terms of stability of all types of buildings, e.g. platforms. It is also necessary to ensure an adequate durability of the rolling stock including, for example, protection in the case of a collision by the usage of crumple zones. It is demanding to ensure an appropriate strength of various structures and all their constituents on normal or exceptional stresses throughout their exploitation. Therefore, specific requirements will have to be used for example in areas with mining damages. Simultaneously, all structures must take into account the risks of fire. Constructions, in case of fire, have to retain its functionality for an adequate long time, for example, stability and cannot facilitate the spread of fire.

\section{Electrical safety}

Whether we used the traction power supply AC $(15 \mathrm{kV} 16.7 \mathrm{~Hz}$ or $25 \mathrm{kV} 50 \mathrm{~Hz}$ AC) or direct current (1.5 kV and $3 \mathrm{kV} \mathrm{DC})$, it is necessary to ensure the electrical safety of people using the railways and people living near the railways in particularly with regard to protection against electric shock.

\section{Protection against fire}

Ensuring security also requires protection against unauthorized access. It is necessary to appropriately restrict access of people to engineering objects, railway systems, traffic control 
and traction power supply. For example, under the protection by unauthorized access should be control room, traction substations, section cabins, devices installed in these tractions and communication devices installed in containers, towers and antenna masts.

Moreover, it is necessary to protect all places where crossing the tracks is allowed. This applies to rail-road crossings, regardless of the category of vehicle, as well as pedestrian crossings, business passing, the ends of the platforms, and wild passing across tracks. An appropriate technical, operational and legal solution should be applied to minimize the inappropriate use of railway crossings.

The safety should be ensured when trains run through tunnels, the viaducts and stations, in particular when they pass through stations without stopping. It is necessary to provide protection in the case of fire, both in terms of minimizing risks, minimizing the effects and maximizing the effectiveness of rescue operations by including emergency exits and escape routes as well as places and means assisting emergency services. Appropriate materials should be used, i.e. non-combustible and non-emitting harmful substances in the case of fire. It is necessary to use such solutions in the rolling stock to continue driving with a fire on board for a sufficiently long period of time. Furthermore, the proper number and functioning of emergency exits and extinguishing agents should be ensured.

\section{Influence of rolling stock forces on track and wheel-rail cooperation}

It is necessary to take into account not only the vertical load of the rolling stock on the railway track and civil engineering objects, but also lateral forces, both related to the centrifugal forces in arcs and the forces associated with zigzag of rolling stock within the acceptable range. Such zigzags occur also in the straight sections of track and result from the tolerance in the spacing of rails and wheels as well as rail wear and tear of rims. It is measured by taper equivalent, which is determined for both tracks and driving rail vehicles. These tolerances cannot be too large to move of trains was stable, but they cannot be too small, because almost all vehicle wheels are installed on the rigid axes and cannot rotate independently, whereas the length of track arcs is obviously different - the outer rail it is always longer, and its wearing is the greater with the smaller radius of the arc. It is also under the influence of the almost always present rigid link between pairs of axes within railway trolleys. For example, a float of single wheels should not happen when vehicles run through arcs of tracks.

Very important are the longitudinal forces from rolling stock. The track is compressed and stretched by longitudinal forces during both starting and braking. It is necessary to ensure an adequate resistance of the track.

Appropriate conditions of friction between the wheels and rails ought to be also ensured. The rolling stock systems are used to counteract spinning wheels and wheel slip. Tractive rolling stock is equipped with the devices for interventional spreading sand on the rails in the front of wheels. The sand should be characterized by appropriate parameters.

Finally, for each vehicle, proper cooperation between wheel and rail should be verified by the use of suitable criteria, from the derailment criterion $\mathrm{Q} / \mathrm{Y}$ to check the peace of race. From that result essential requirements for braking systems used in vehicles, service braking, the emergency brake, the parking brake and even track brakes used in marshalling stations. It is 
necessary to ensure an adequate braking capacity at full speed even at the maximum speed limit due to the long braking distances.

These issues must take into account devices and railway traffic control systems, including the distribution of signal lights, to ensure their visibility. The impact of cooperation on the wheel-rail braking curves used by the control systems of safe driving should be also included.

\section{Control of railway traffic}

Active safety systems should be used in the form of signalling systems. Sufficiently safe ought to be signal boxes to exclude setting contrary train runs in different railway stations. Properly secure must be: line blockades managing successions of trains on routes between stations, systems controlling unoccupied tracks and crossovers, and railway crossings. Accordingly safe must be communication and control systems and those based on the transmission of secure information from the track to the vehicle for the safe running of trains. Such systems not only have to implement features to ensure safety but also need to be safe systems. Their damage cannot lead to security risk. Relevant requirements must be complied with: traffic lights, crossover drives, systems for detection of faults in rolling stock.

Safe must be a link between systems, for example, between the control systems used in the neighbouring districts, and between station and linear devices - the interlocking and blockade. The same applies to the transfer of information from devices controlling nonoccupancy to interlocking and from interlocking to radio control centre as well as from circuits of traffic lights to balis encoders used to transfer electronic permits for pass of vehicles equipped with the safety control devices.

The devices of safety control must guarantee the safety at the level corresponding to the aims set for the network, in terms of receiving electronic information, its verification, monitoring the compliance of the vehicle pass with the information, as well as implementation of intervention braking according to the class control system, automatic warning, automatic control, automatic steering and automatic driving the train.

\section{Influence of power system on control devices}

It is also appropriate to exclude the negative impact of supply equipment and other electrical devices on the safety and functionality of the control systems in both the rolling stock and infrastructure. Using the traction power requires the closing electrical circuit. The current drawn from the substation via the traction network and the pantograph is transmitted to the engine only if it can flow back to the traction substation. For the purpose, the return traction networks are used. It is necessary to adequately and effectively prevent interference which can generate return currents in devices control motion. The traction current occurring in rails, when train is passing, cannot interfere with the operation of electric track circuits used as the system controlling non-occupancy of tracks. The currents present in the return network and frequently occurring stray currents cannot interfere with transmissions between the indoor traffic controls installed in control rooms, for example, in transmitters and external devices such as axle counters, signalling devices and rail switches. 
It is necessary to take into account the impact of harmonics, acceptable levels of interference from systems and traction devices as well as required levels of resistance to these noises. The levels must be guaranteed by systems and railway traffic control devices.

\section{Traffic regulations and qualifications of personnel}

The essential requirement 'safety' is also a need for consistent rules for traffic control to ensure the safety of transport not only in normal conditions at efficient devices of railway traffic control but also in fault conditions including failures in equipment and control communication devices as well as in the case of track closures, accidents and other railway events. This requires very precisely defined rules of working personnel having an impact on the safety of railway traffic. It especially concerns train dispatchers and drivers. It is necessary to take into account the use of the same infrastructure by many carriers independently training drivers. It should be also considered the interface between the different Infrastructure managers, when operating rules change during the train passage.

Qualifications of drivers should be sufficiently confirmed by appropriate skills of driving a particular type of vehicle, knowledge about traffic regulations valid in a given area, appropriate knowledge of the route, revised medical and mental health as well as linguistic skills. The relevant demands are also made for other staff and workers employed in traffic control centres to ensure safe operation, both in a given country and abroad. The essential requirement 'safety' includes the protection of any device intended for use in such a way to not negatively influence on the safe functioning of these devices, as well as health and safety of users, even if they are used in a manner inconsistent with the recommendations.

Safety regulations also define requirements for carriage of dangerous goods. It must be noted, however, that this issue is dedicated to a separate directive on the transport of dangerous goods. There is separate Polish law and detailed regulations including ADR for road and RID for railway transport.

\section{Preventing panic}

In the field of interoperability, the conditions of carriage all kinds of high-risk goods are not defined in details. However, defined, in terms of interoperability in relation to the essential requirement 'safety', are requirements for additional protection of passenger by providing individual and broadcast communications in the case of emergency between passengers, members of the team train and driver. The essential requirement 'safety' includes a number of technical and operational requirements. Their use protects passengers in emergency situations and prevents panic. This concerns emergency braking available for passengers, emergency lighting, the use of appropriate systems of opening and closing external and interior door and communications in trains.

\section{Informatics support of railway safety}

With respect to the essential requirement 'safety' imposed on legal provisions it is also demanding the use of appropriate systems and equipment for the collection, storage and transmission of information concerning security.

\section{Technical specifications for interoperability and normative documents}


The essential requirement 'safety' requires technical, operational and regulatory aspects, which in the above-discussed areas provide security "in the proper way", "the right way", "effectively", "at the appropriate level", etc. The fact that the essential requirement is met is confirmed in the framework of the so-called conformity assessment process conducted by an independent competent body. These units are based on the specific requirements, whose fulfilling enable to fulfil the essential requirements. We already mentioned technical specifications for interoperability in the third chapter. It describes in details the link between the essential and specific requirements, which are defined for the subsystems in the fourth section, whereas for selected elements defined as interoperability components, which are products on the European railway markets, are described in the fifth section. Additionally, specific requirements for selected elements referred to as types of buildings and types of devices that are products on the Polish railway market are given in the so-called list of the President of the Office for Railway Transport [8, 9] indicating clearly their link with the essential requirements, and in particular with the essential requirement 'safety'.

Security requirements in a general but complete way define the essential requirements stated on several individual pages. The same requirements are then linked with the detailed requirements in the aforementioned fourth and fifth chapters of the TSI and the list of UTK president in total on several hundred pages. They are not there, however, given in sufficient details that it was not necessary to look into the more detailed documents. This role is played primarily by European norms.

EN standards or their Polish counterparts PN-EN indicated as applicable respectively in the TSI or the list of UTK president must be applied. The standards, which have the status of standards compatible with the directive on interoperability but are not indicated in the TSI are strongly recommended. Their use is a presumption to meet the essential requirements to which they are related, of course in the area to which they relate. Their use is not mandatory. The essential requirement can be met in another way, provided that it is properly good in the case of the requirements 'safety', provided that the solution adopted will ensure, at least the same level of safety as the one described in the compatible standard.

TSI specifications as applicable provide also many other documents referred as the European technical specifications. This applies particularly to the specifications of the European Train Control System (European Train Control System - ETCS), Global System for Mobile Communications (Global System for Mobile communication - Rail - GSM-R), and telematics applications.

\section{Summary - modernization and construction of railway lines and rolling stock}

All these regulations are applicable to the modernization and construction of railways and rolling stock. Their use is evident in the construction of a new line or production of new vehicle. Somewhat more difficult is the modernization. Not every work carried out on the railroad tracks, railway stations, rolling stock are modernization. Whether work, for example, implemented as part of the investment commissioned in the tender for the modernization of the line, actually have a range that causes, from the legal point of view, the line that is modernized requires individual assessment in each case. The title of the project does not prejudge whether we are dealing with the modernization or renewal of the infrastructure and 
rolling stock. Of course, we also have such projects, where the title suggests that we are not dealing with the modernization even though the scope of the project leads to the conclusion that modernization and essential requirements including the requirement 'safety' with TSI specifications take place. When the answer to the question about the presence of modernization is not obvious, we should turn to the Railway Transport Office. It has a legal duty to take the binding decision in the scope of the particular projects.

Of course, safety must be ensured when performed works are not modernization and when no works are carried out at all. Security of the entire railway transport system must be provided regardless of whether the concept of the essential requirements existed or not at the time when the exploitation of a given vehicle or in a given line started. It is regulated by the directive on safety in railway transport [1]. It is therefore necessary to ensure the safety in much broader scope. Here, the European law imposed also certain rules, which I will discuss in a fully complementary article "Rail safety in the context of the relationship between the directives on safety railway and on railway interoperability - analysis from the point of view of safety management", which I hope will be published in the next issue of the Review Communication.

\section{Source materials}

[1] Directive 2004/49 / EC of the European Parliament and of the Council of 29 April 2004. On safety on the Community's railways and amending Council Directive 95/18 / EC on the licensing of railway undertakings and Directive 2001/14 / EC on the allocation of capacity railway infrastructure and the levying of charges for the use of railway infrastructure and safety certification (Dz.U.UE.L.2004.164.44)

i. amended by:

- Directive of the European Parliament and of the Council 2008/110 / EC of 16 December 2008. Amending Directive 2004/49 / EC on safety on the Community's railways (Directive on railway safety) (Dz.U.UE.L.2008.345.62)

- Commission Directive 2009/149 / EC of 27 November 2009. Amending Directive 2004/49 / EC of the European Parliament and of the Council as regards Common Safety Indicators and common methods to calculate accident costs (Dz.U.UE.L.2009.313.65)

[2] Directive of the European Parliament and Council Directive 2008/57 / EC of 17 June 2008. On the interoperability of the rail system within the Community

(Dz.U.UE.L.2008.191.1)

i. amended by:

- Commission Directive 2009/131 / EC of 16 October 2009. Amending Annex VII to the European Parliament and Council Directive 2008/57 / EC on the interoperability of the rail system within the Community (Dz.U.UE.L.2009.273.12)

- Commission Directive 2011/18 / EU of 1 March 2011. Amending Annexes II, V and VI to Directive of the European Parliament and Council Directive 2008/57 / EC on the interoperability of the rail system within the Community (Dz.U.UE.L.2011.57. 21)

- Commission Directive 2013/9 / EU of 11 March 2013. Amending Annex III to the Directive of the European Parliament and Council Directive 2008/57 / EC on the interoperability of the rail system within the Community (Dz.U.UE.L.2013.68.55)

- Commission Directive 2014/38 / EU of 10 March 2014. Amending Annex III to the Directive of the European Parliament and Council Directive 2008/57 / EC as regards the noise level (Dz.U.UE.L.2014.70.20)

- Commission Directive 2014/106 / EU of 5 December 2014. Amending Annexes V and VI to Directive of the European Parliament and Council Directive 2008/57 / EC on the interoperability of the rail system within the Community (Dz.U.UE.L.2014.355.42) 
[3] Regulation of the Minister of Infrastructure and Development of 21 July 2015. On common safety indicators (CSI) (Dz. U. 2015, pos. 1061)

[4] Regulation of the Minister of Transport dated 19 March 2007. On the safety management system in railway transport Journal. U. 2007, No. 60, item. 407

i. amended by:

- Regulation of the Minister of Infrastructure of 17 February 2015. Amending Regulation on the safety management system in railway transport (Dz. U. 2015, Pos. 264)

- Regulation of the Minister of Infrastructure of 22 May 2009. Amending Regulation on the safety management system in railway transport (Dz. U. 2009, n. 91, pos. 744)

[5] Regulation of the Minister of Transport of 5 December 2006. On how to obtain a safety certificate - Acts. U. 2006, No. 230, item. 1682

i. amended by:

- Regulation of the Minister of Infrastructure and Development of 6 February 2015. Amending the regulation on how to obtain a safety certificate (OJ 2015 pos. 232)

- Regulation of the Minister of Infrastructure and Development of 25 September 2015. On the terms and conditions for the issuance, changes and revocation of security, safety certificates and safety certificates (Dz. U. 2015, pos. 1548)

[6] Regulation of the Minister of Infrastructure and Development 720/2014 of 13 May 2014. On the acceptance of certain types of buildings, equipment and rail vehicles (Dz.U.2014.720)

[7] Regulation of the Minister of Infrastructure and Construction 254/2016 of 25 February 2016 on the interoperability of the rail system (Dz.U.2016.254)

[8] Regulation of the Minister of Transport, Construction and Maritime Economy 43/2013 of 27 December 2012. On the list of the relevant national technical specifications and standardization documents, the use of which enables the essential requirements for interoperability of the rail system (Dz.U.2013.43)

[9] List of the President of the Railway Transport Office on the relevant national technical specifications and standardization documents, the use of which enables the essential requirements for interoperability of the rail system of 26 September 2013. 